\title{
Prevalence and comorbidity of migraine headache: results from the Singapore Mental Health Study 2016
}

\author{
Anitha Jeyagurunathan ${ }^{1}$ (D) Edimansyah Abdin ${ }^{1} \cdot$ Janhavi Ajit Vaingankar $^{1} \cdot$ Boon Yiang Chua ${ }^{1} \cdot$ Saleha Shafie $^{1}$. \\ Shi Hui Sherilyn Chang ${ }^{1} \cdot$ Lyn James $^{2} \cdot$ Kelvin Bryan Tan $^{2} \cdot$ Sutapa Basu ${ }^{3} \cdot$ Siow Ann Chong ${ }^{1} \cdot$ Mythily Subramaniam $^{1}$
}

Received: 6 February 2019 / Accepted: 20 August 2019 / Published online: 27 August 2019

(c) The Author(s) 2019

\begin{abstract}
Background and aim Migraine is a highly prevalent and disabling neurological disorder associated with a wide range of psychiatric comorbidities. Studies have revealed that those with migraine headache and coexisting psychiatric disorders have poorer treatment outcomes and increased disability. The study aims to establish the prevalence, correlates, and comorbidities of migraine headache among the multi-ethnic Asian population in Singapore.

Method Data were extracted from the Singapore Mental Health Study 2016 (SMHS 2016), a cross-sectional epidemiological survey of a nationally representative sample. Face-to-face interviews were completed with 6126 participants between 2016 and 2017. The data relating to chronic medical conditions, psychiatric conditions, and 30-day functioning and disability were captured using the World Mental Health Composite International Diagnostic Interview (CIDI) version 3.0.

Results The lifetime prevalence for migraine headache in the Singapore general population was $8.2 \%$. Malay ethnicity (versus Chinese), female gender (versus male), and diploma holders (versus university) were significantly more likely to experience migraine headache. Participants belonging to the older age group (65 years and above versus 18-34 years of age), and those who were economically inactive (versus employed) were less likely to experience migraine headache. The mean age of onset for migraine was 26.4 years $(\mathrm{SD}=11.1)$. Poisson regression analyses showed that migraine headache was also significantly associated with psychiatric conditions such as major depressive disorder (MDD) (prevalence ratio (PR), 1.80; 95\% CI, 1.25-2.58), bipolar disorder (BD) (PR, 3.55; 95\% CI, 2.29-5.51), generalized anxiety disorder (GAD) (PR, 2.04; 95\% CI, 1.12-3.69), obsessive compulsive disorder (OCD) (PR, 2.20; 95\% CI, 1.49-3.26), and alcohol use disorder (AUD) (PR, 1.93; 95\% CI, 1.20-3.08). Those with migraine headache were significantly associated with poor functioning and disability compared to those without migraine headache.

Conclusions and discussion Our study showed significant associations between migraine headache and psychiatric disorders, as well as with role functioning and disability. The findings of our study emphasise the need for screening for psychiatric comorbidity among those with migraine and the development of appropriate interventions for this group.
\end{abstract}

Keywords Epidemiology $\cdot$ Migraine $\cdot$ Mental disorders $\cdot$ Prevalence $\cdot$ Asian

\section{Introduction}

Migraine is an under-recognised and underdiagnosed disorder that is characterised by recurrent headache, sensitivity to light, nausea, and reduced functioning [1]. Migraine affects 1 out of every 10 individuals globally [2]. The World Health Organization (WHO) ranked migraine as one of the 20 most disabling medical illnesses in the world [3]. According to

Anitha Jeyagurunathan

anitha_jeyagurunathan@imh.com.sg

Extended author information available on the last page of the article the current diagnostic criteria of the International Headache Society (IHS), studies have shown that lifetime prevalence of migraine is higher in Western (European and North American) countries and lower in Asian countries [4, 5]. Studies conducted in developed Western countries have revealed that migraine affects approximately $20 \%$ of the general population over their lifetime [6, 7], while epidemiological studies conducted in Asia reported an overall lifetime prevalence of migraine ranging from 8.4 to $12.7 \%$ [8].

Migraine is also associated with a wide range of psychiatric comorbidities $[9,10]$. Recent studies have reported that anxiety and mood disorders are approximately two to ten 
times more common among those with chronic migraine in the general population [9]; stress-related disorders, and post-traumatic stress disorders are similarly associated with migraine [11]. The significant comorbidity observed between migraine and psychiatric illnesses may be a result of common genetic or environmental factors, progesterone processing, and oestrogen response which is thought to play an important role in the pathophysiology of migraine and mood disorders, and lastly chronic and severe migraine may also cause or contribute to psychiatric illnesses $[12,13]$. Other identified risk factors of migraine include medication overuse (such as Triptans, Opioids and Ergot alkaloids) [14], obesity, and sleep problems $[15,16]$.

Depending on the level of severity, migraine often has a direct and immediate impact on an individual's daily living activities. It leads to withdrawal from social and leisure activities, loss of work or school days, and inability to lead a productive life which ultimately affects the quality of life and results in disability among individuals $[17,18]$. Studies have revealed that patients with migraine headache and with coexisting psychiatric disorders are associated with poorer treatment outcomes and increased disability as compared to migraine headache without comorbid psychiatric conditions $[9,19,20]$.

Socio-demographic characteristics including age, gender, ethnicity, employment status, education, and income level have frequently been associated with migraine headaches $[20,21]$. A study conducted in Turkey revealed that migraine was more prevalent in women and among those with lower income and lower education [22]. Other studies conducted in United States have similarly reported that the prevalence and severity of migraine were more likely to be higher among women, those who were unemployed and those with lower socioeconomic status [23], while a study from Singapore conducted among patients with migraine reported that migraine was more likely to be higher among those of Malay ethnicity [24].

Data on prevalence, characteristics, comorbidity, and disability associated with migraine headaches in South-East Asia are limited. In 2010, a population-wide epidemiological study conducted in Singapore- the Singapore Mental Health Study (SMHS 2010)—was the first to establish the lifetime prevalence of migraine headache as $5.6 \%$ and that migraine was significantly associated with psychiatric disorders. Those with migraine were two times more likely to have major depressive disorder (MDD) and alcohol use disorder (AUD), and three times more likely to have generalized anxiety disorder (GAD) [20]. Following the completion of the second Singapore Mental Health Study conducted in 2016 (henceforth referred to as SMHS 2016) [25], the authors were interested in understanding whether there were any changes in the prevalence and correlates of migraine since the last survey and if the geographic and ethnic diversity observed in the last survey would persist in the current survey. Thus, the aims of the current article were to (1) establish the prevalence, correlates and comorbidity of migraine headache among the general population of Singapore, (2) examine changes, if any, in the prevalence of migraine since the last survey-SMHS 2010, (3) assess the extent of role disability among individuals with migraine headache, and finally, (4) examine the comorbidity of common psychiatric disorders with migraine headache in this population.

\section{Methods}

\section{Sample}

Singapore is a multi-ethnic country in South-East Asia, with a resident population of 3.8 million [26] of which $74.2 \%$ are Chinese, $13.3 \%$ are Malays, $9.1 \%$ are Indians, and 3.3\% belong to other ethnic groups. The SMHS 2016 was a crosssectional epidemiological household survey conducted among Singapore citizens and permanent residents, aged 18 years and above who were living in Singapore between 2016 and 2017, and randomly selected from an administrative database. A disproportionate stratified sampling was used, where the three main ethnic groups (Chinese, Malay, and Indians) were sampled in an equivalent proportion of about $30 \%$ each rather than in proportion to the ethnic distribution in the general population. Participants living outside Singapore, those who were unable to be contacted due to an incomplete or incorrect address, those residents who were incapable of doing an interview due to severe physical and mental conditions, and those who were unable to complete the interview in one of the specified languages were excluded from the survey. Face-to-face interviews were conducted at the respondents' homes or another preferred location and respondents completed the intervieweradministered questionnaire in English, Chinese, and Malay according to their preference.

The study was approved by the National Healthcare Groups' Domain Specific Review Board. Written informed consent was taken from all respondents who were 21 years and above as well as from the legally acceptable representative, parents, or guardians of respondents who were aged 18-20 years. The survey was administered using computerassisted personal interview (CAPI) methods by professional survey interviewers who had been trained and supervised by the study team at the Institute of Mental Health (IMH). The SMHS 2016 methodology has been described in greater detail elsewhere [25]. 


\section{Assessments}

\section{Socio-demographic information}

Socio-demographic information obtained included age at interview (18-34, 35-49, 50-64, or 65 years and above), gender, ethnicity (Chinese, Malay, Indian, or Others), marital status (never married, married, divorced/separated, or widowed), educational level (primary and below, secondary, vocational institute, pre-university/junior college, diploma, or university), employment status (employed, economically inactive, or unemployed), and household income in Singapore dollars (SGD) (below 2000, 2000-3999, 4000-5999, 6000-9999, 10,000 and above).

\section{Chronic physical conditions}

A modified version of the World Mental Health Composite International Diagnostic Interview (CIDI) version 3.0 [27] checklist of chronic medical conditions was used and the respondents were asked to report any of the conditions listed in the checklist. The question was read as, "I am going to read to you a list of health problems some people have. Has a doctor ever told you that you have any of the following chronic medical conditions?" This was followed by a list of 18 chronic physical conditions (such as asthma, high blood sugar, hypertension, arthritis, cancer, neurological condition, Parkinson's disease, stroke, congestive heart failure, heart disease, back problems, stomach ulcer, chronic inflamed bowel, thyroid disease, kidney failure, migraine headache, chronic lung disease, and hyperlipidaemia) which were considered to be prevalent among Singapore's population. Among these chronic medical conditions, only data on migraine headache was analysed in this paper. If the participant gave a positive response for any of the conditions listed, they were then asked, "How old were you when you were diagnosed with the medical condition"? and, "Did you receive any treatment for it at any time during the past 12 months?".

\section{Psychiatric disorders}

The diagnoses of psychiatric disorders were established using CIDI version 3.0 diagnostic modules. This provided lifetime and 12-month prevalence of disorders according to the International Classification of Disease, 10th Revision (ICD-10) and Diagnostic and Statistical Manual of Mental Disorders, 4th Edition (DSM-IV) psychiatric classification systems. In the survey, the following disorders were assessed: major depressive disorder (MDD), bipolar disorder (BD), generalized anxiety disorder (GAD), obsessive compulsive disorder (OCD), and alcohol use disorder (AUD). Diagnoses were generated by running algorithms using rules of hierarchy on de-identified data by trained researchers.

\section{0-day functioning and disability (FD)}

The measure of role disability was assessed using CIDI 30-day functioning and disability module: the questions asked the participants about overall impairment due to all the physical and mental health problems and how it interfered with the participant's life and activities during the past 30 days. The questions was read as "how many days out of the past 30 days were you: "totally unable to work/ carry out normal activities", had to "cut down on work/not get as much done", "cut back on quality/how carefully you worked", and it took an "extreme effort to perform up to your usual level".

\section{Statistical analyses}

Statistical analyses were carried out with Statistical Analysis Software (SAS) version 9.3 [28]. To ensure that survey findings were representative of the Singapore adult population, the data were weighted to adjust for oversampling and poststratified by age and ethnicity between the survey sample and the Singapore resident population in 2014. Descriptive analyses were performed to establish the prevalence of migraine headache and comorbid psychiatric disorders (MDD, BD, GAD, OCD, and AUD) based on weighted data. Prevalence of lifetime disorder was estimated from the proportion of participants who had ever received a diagnosis of a chronic condition by a clinician up to their age at interview, while the 12-month proportion was estimated as those who experienced the condition at some point during the year prior to the interview. Poisson regression analysis [29] was used to examine the associations between migraine headache and socio-demographic variables as well as psychiatric disorders. The socio-demographic covariates were chosen based on the past research studies. Age [7, 30], gender [21, 23, 30], ethnicity [20, 31], education level [22], and employment status [23] have been associated with migraine headache and were hence included in the current study. In accordance with McWilliams et al's methodology, to elucidate the relationship between migraine headache, significant sociodemographic variables and comorbid psychiatric disorders while accounting for other variables that may have independent effects on psychopathology, three series of Poisson regression models were used [32]. In the first Poisson model, prevalence ratios (PRs) for the association between migraine headache and psychiatric disorders were adjusted for sociodemographic variables such as age, gender, ethnicity, 
education level, and employment status. The second Poisson regression model was adjusted for the significant sociodemographic variables (such as age, gender, ethnicity, education level, and employment status) and presence of other chronic physical conditions. The third Poisson regression model was adjusted for the significant socio-demographic variables, other chronic physical conditions, and psychiatric disorders. Standard errors (SE) and significant tests were estimated using the Taylor series' linearization method to adjust for the weighting. Multivariate significant was evaluated using Wald X2 tests based on design corrected coefficient variance-covariance matrices. In addition, the mean score of role functioning and disability among individuals with migraine headache and individuals without migraine headache were assessed using a linear regression model after controlling for significant socio-demographic variables including age, gender, ethnicity, education level, and employment status. Statistical significance was evaluated at the 0.05 level with two-sided tests.

\section{Results}

\section{Socio-demographic characteristics of the sample}

The socio-demographic characteristics of the participants are shown in Table 1. A total of 6126 participants completed the study giving a response rate of $69.5 \%$. Six thousand one hundred and ten individuals responded to the questions on chronic physical conditions (migraine headache) and were included in this study. The sample comprised an equivalent proportion of male $(49.6 \%)$ and female $(50.4 \%)$. A majority of the sample was aged between 18 and 34 years (30.4\%), of Chinese ethnicity $(75.7 \%)$, married (59.8\%), with university education level (29.4\%), employed (72.0\%) and with a monthly household income of (4000-5999) Singapore dollars (21.4\%).
Table 1 Socio-demographic characteristics of the respondents

\begin{tabular}{|c|c|c|c|c|}
\hline Variables & Category & $n(6126)$ & Unweighted \% & Weighted \% \\
\hline \multirow[t]{4}{*}{ Age group (in years) } & $18-34$ & 1707 & 27.90 & 30.40 \\
\hline & $35-49$ & 1496 & 24.40 & 29.60 \\
\hline & $50-64$ & 1626 & 26.50 & 26.90 \\
\hline & $65+$ & 1297 & 21.20 & 13.10 \\
\hline \multirow[t]{2}{*}{ Gender } & Male & 3068 & 50.08 & 49.60 \\
\hline & Female & 3058 & 49.90 & 50.40 \\
\hline \multirow[t]{4}{*}{ Ethnicity } & Chinese & 1782 & 29.10 & 75.70 \\
\hline & Malay & 1990 & 32.50 & 12.50 \\
\hline & Indian & 1844 & 30.10 & 8.70 \\
\hline & Others & 510 & 8.30 & 3.10 \\
\hline \multirow[t]{4}{*}{ Marital status } & Never married & 1544 & 25.20 & 31.00 \\
\hline & Married & 3843 & 62.70 & 59.80 \\
\hline & Divorced/separated & 343 & 5.60 & 5.30 \\
\hline & Widowed & 396 & 6.50 & 4.10 \\
\hline \multirow[t]{6}{*}{ Education } & Primary and below & 1187 & 19.40 & 16.30 \\
\hline & Secondary & 1648 & 26.90 & 23.00 \\
\hline & Pre-U/junior college & 304 & 4.96 & 6.00 \\
\hline & Vocational institute/ITE & 508 & 8.30 & 6.30 \\
\hline & Diploma & 1024 & 16.70 & 19.00 \\
\hline & University & 1455 & 23.75 & 29.40 \\
\hline \multirow[t]{3}{*}{ Employment status } & Employed & 4055 & 66.20 & 72.00 \\
\hline & Economically inactive & 1716 & 28.02 & 22.70 \\
\hline & Unemployed & 354 & 5.80 & 5.30 \\
\hline \multirow{5}{*}{$\begin{array}{l}\text { Household income } \\
\text { (SGD) }\end{array}$} & Below 2000 & 1147 & 16.50 & 16.50 \\
\hline & 2000-3999 & 1331 & 20.01 & 20.00 \\
\hline & $4000-5999$ & 1113 & 21.40 & 21.40 \\
\hline & 6000-9999 & 1003 & 2.20 & 2.20 \\
\hline & 10,000 and above & 861 & 20.30 & 20.30 \\
\hline
\end{tabular}

ITE Institute of Technical Education, SGD Singapore dollars 


\section{Prevalence of migraine headache and its socio-demographic correlates}

The lifetime prevalence estimates for migraine headache in the current sample of Singapore general population were $8.2 \%(n=516)$. The mean age of onset of migraine was 26.4 years $(\mathrm{SD}=11.14)$. In all $34.3 \%$ of participants with migraine had received treatment in the past 12 months. Table 2 shows the socio-demographic correlates of migraine headache. Age, gender, ethnicity, education level,

Table 2 Socio-demographic correlates of migraine headache

\begin{tabular}{|c|c|c|}
\hline \multirow[t]{2}{*}{ Variables } & \multicolumn{2}{|c|}{ Migraine headache } \\
\hline & PR & $95 \% \mathrm{CI}$ \\
\hline \multicolumn{3}{|l|}{ Age group (in years) } \\
\hline $18-34$ & Reference & \\
\hline $35-49$ & 0.91 & $0.65-1.27$ \\
\hline $50-64$ & 0.78 & $0.51-1.20$ \\
\hline $65+$ & 0.44 & $0.21-0.93$ \\
\hline \multicolumn{3}{|l|}{ Gender } \\
\hline Male & Reference & \\
\hline Female & 2.42 & $1.84-3.18$ \\
\hline \multicolumn{3}{|l|}{ Ethnicity } \\
\hline Chinese & Reference & \\
\hline Malay & 1.48 & $1.15-1.89$ \\
\hline Indian & 1.10 & $0.87-1.41$ \\
\hline Others & 1.05 & $0.71-1.54$ \\
\hline \multicolumn{3}{|l|}{ Marital status } \\
\hline Never married & Reference & \\
\hline Married & 1.21 & $0.86-1.71$ \\
\hline Divorced/separated & 1.29 & $0.72-2.29$ \\
\hline Widowed & 0.47 & $0.20-1.09$ \\
\hline \multicolumn{3}{|l|}{ Education } \\
\hline University & Reference & \\
\hline Primary and below & 0.65 & $0.36-1.16$ \\
\hline Secondary & 0.89 & $0.60-1.33$ \\
\hline Pre-U/junior college & 1.05 & $0.57-1.91$ \\
\hline Vocational institute/ITE & 1.35 & $0.81-2.25$ \\
\hline Diploma & 1.43 & $1.01-2.02$ \\
\hline \multicolumn{3}{|l|}{ Employment } \\
\hline Employed & Reference & \\
\hline Economically inactive & 0.70 & $0.49-0.99$ \\
\hline Unemployed & 0.84 & $0.45-1.59$ \\
\hline \multicolumn{3}{|l|}{ Household income (SGD) } \\
\hline 10,000 and above & Reference & \\
\hline Below 2000 & 0.82 & $0.50-1.35$ \\
\hline 2000-3999 & 1.24 & $0.83-1.87$ \\
\hline 4000-5999 & 1.06 & $0.70-1.61$ \\
\hline 6000-9999 & 1.27 & $0.86-1.88$ \\
\hline
\end{tabular}

95\% CI 95\% confidence interval, ITE Institute of Technical Education, $P R$ prevalence ratio, $S G D$ Singapore dollars and employment status were significantly associated with migraine headache. Participants belonging to the age group of 65 years and above (PR, 0.44; 95\% CI, 0.21-0.93) (versus 18-34 years of age), and those who were economically inactive (PR, 0.70; 95\% CI, 0.49-0.99) (versus employed) were less likely to experience migraine headache. Those of Malay ethnicity (PR, 1.48; 95\%CI, 1.15-1.89) (versus Chinese), females (PR, 2.42; 95\% CI, 1.84-3.18) (versus males), and with a diploma (PR, 1.43; 95\% CI, 1.01-2.02) (versus university education) were significantly more likely to experience migraine headache.

\section{Prevalence ratio of psychiatric disorders among those with migraine}

Table 3 shows the prevalence ratio (PR) of psychiatric disorders among those with migraine headache. The prevalence ratio of MDD (PR, 2.10; 95\% CI, 1.47-3.01), BD (PR, 4.36; 95\% CI, 2.83-6.72), GAD (PR, 2.42; 95\% CI, 1.34-4.35), OCD (PR, 2.75; 95\% CI, 1.85-4.09), and AUD (PR, 1.60; 95\% CI, 1.00-2.56) was significantly higher among individuals with migraine headache.

\section{Association between migraine headache and psychiatric disorders}

Table 4 presents the association between migraine headache and psychiatric disorders. The first model of Poisson regression analysis adjusting for socio-demographic variables shows that those with migraine headache were significantly associated with all psychiatric disorders compared with those without migraine headache. The second model of Poisson regression used to examine the association, adjusted for significant socio-demographic variables, and the presence of any of the 17 other chronic physical conditions revealed that those with migraine headache remained significantly associated with all psychiatric disorders compared with those not having migraine headache. The third model of Poisson regression, adjusted for significant socio-demographic variables, 17 chronic physical conditions, and psychiatric

Table 3 Prevalence ratio of psychiatric disorder in migraine headache condition

\begin{tabular}{llll}
\hline Psychiatric disorder & \multicolumn{3}{c}{ Migraine headache $(n=516)$} \\
\cline { 2 - 4 } & $\%$ & PR & $95 \%$ CI \\
\hline Major depressive disorder & 6.3 & 2.10 & $1.47-3.01$ \\
Bipolar disorder & 1.6 & 4.36 & $2.83-6.72$ \\
Generalized anxiety disorder & 1.6 & 2.42 & $1.34-4.35$ \\
Obsessive compulsive disorder & 3.6 & 2.75 & $1.85-4.09$ \\
Alcohol use disorder & 4.7 & 1.60 & $1.00-2.56$ \\
\hline
\end{tabular}

95\% CI 95\% confidence interval, $P R$ prevalence ratio 
Table 4 Association between migraine headache and psychiatric disorders

\begin{tabular}{|c|c|c|c|c|c|c|}
\hline \multirow[t]{2}{*}{ Psychiatric disorders } & \multicolumn{2}{|c|}{ Model $1^{\mathrm{a}}$} & \multicolumn{2}{|c|}{ Model $2^{b}$} & \multicolumn{2}{|c|}{ Model $3^{c}$} \\
\hline & PR & $95 \% \mathrm{CI}$ & PR & $95 \% \mathrm{CI}$ & PR & $95 \% \mathrm{CI}$ \\
\hline Major depressive disorder & 1.80 & $1.25-2.58$ & 1.73 & $1.19-2.50$ & 1.60 & $1.08-2.37$ \\
\hline Bipolar disorder & 3.55 & $2.29-5.51$ & 3.26 & $2.15-4.94$ & 2.70 & $1.70-4.29$ \\
\hline Generalized anxiety disorder & 2.04 & $1.12-3.69$ & 1.87 & $1.02-3.41$ & 1.31 & $0.69-2.48$ \\
\hline Obsessive compulsive disorder & 2.20 & $1.49-3.26$ & 2.33 & $1.59-3.42$ & 1.72 & $1.15-2.55$ \\
\hline Alcohol use disorder & 1.93 & $1.20-3.08$ & 1.79 & $1.12-2.86$ & 1.42 & $0.89-2.26$ \\
\hline
\end{tabular}

95\% CI 95\% confidence interval, $P R$ prevalence ratio

${ }^{a}$ First model of Poisson regression analysis adjusted for socio-demographic variables shows that migraine headache was significantly associated with all psychiatric disorders (model 1)

${ }^{b}$ Second model of Poisson regression analysis adjusted for socio-demographic variables shows that migraine headache was significantly associated with other physical conditions (model 2)

${ }^{c}$ Third model of Poisson regression analysis adjusted for significant socio-demographic variables, other chronic physical conditions and psychiatric disorders revealed that migraine headache remained significantly associated with psychiatric disorders (model 3) disorders, revealed that those with migraine headache remained significantly associated with MDD (PR, 1.60; 95\% CI, 1.08-2.37), BD (PR, 2.70; 95\% CI, 1.70-4.29), and OCD (PR, 1.72; 95\% CI, 1.15-2.55) compared with those not having migraine headache. The associations between migraine and age, gender, ethnicity, education level, and employment status were statistically significant in the first model, whereas in the second and third models, age, gender, ethnicity, and education level remained statistically significant. Employment status was not significant in the second and third models of Poisson regression.

\section{0-day functioning and disability (FD) among individual with and without migraine}

Table 5 shows the mean 30-day functioning and disability (FD) among individuals with and without migraine headache. After adjusting for significant socio-demographic variables, those with migraine headache were significantly associated with poorer functioning and disability, had to "cut down on work/not get as much done" $(P=0.03)$, "cut back on quality/how carefully you worked" $(P=0.01)$, and it took an "extreme effort to perform up to your usual level" $(P=0.01)$ as compared to those without migraine headache.

\section{Discussion}

The current results indicate that migraine headache is a fairly common chronic physical condition in Singapore. The lifetime prevalence estimates for migraine headache in the Singapore general population were $8.2 \%$. The prevalence has increased significantly from the previous local study conducted in 2010 (5.6\%) [20]. The increase in the prevalence of migraine could be due to more individuals seeking treatment for headaches and receiving a diagnosis of migraine as compared to the previous study. Other reasons include higher stress [33], or unhealthy lifestyle habits such as low physical activity and obesity [34] in the population. According to National Population Health Survey 2016/17 in Singapore, overall trends for obesity and overweight have increased from 34.3 (2013) to $36.2 \%$ (2017); similarly, binge drinking continued to increase over the years from 7.7 (2013) to $9.0 \%$ (2017) [35]. These associations among lifestyle factors and migraine have been reported in other studies [36, 37]. The above-mentioned possible changes in
Table 5 30-day functioning and disability (FD) among with and without migraine

\begin{tabular}{llll}
\hline How many days out of the past 30 days: & $\begin{array}{l}\text { With migraine } \\
\text { mean } \pm \text { SE }\end{array}$ & $\begin{array}{l}\text { Without } \\
\text { migraine } \\
\text { mean } \pm \text { SE }\end{array}$ & $P$ value \\
\hline FD4 "totally unable to work/carry out normal activities" & $0.43 \pm 0.07$ & $0.27 \pm 0.03$ & 0.723 \\
FD7 "cut down on work/not get as much done" & $0.97 \pm 0.19$ & $0.57 \pm 0.06$ & $0.03 * *$ \\
FD8 “cut back on quality/how carefully you worked" & $1.08 \pm 0.25$ & $0.41 \pm 0.05$ & $0.006^{* *}$ \\
FD9 "extreme effort to perform up to your usual level" & $0.83 \pm 0.19$ & $0.30 \pm 0.04$ & $0.005^{* *}$ \\
\hline
\end{tabular}

**Statistically significant $P$ values $(P<0.05)$ 
lifestyle factors could cause increase in migraine prevalence among the general population in Singapore. However, the prevalence of migraine is lower in Singapore's population compared with that reported in Western populations. Studies from United States have reported the prevalence of migraine to be $15.7 \%$, while a Canadian population survey reported it to be $12.0 \%$ [38, 39]. About one-third $(34.3 \%)$ of participants in our study with migraine received treatment in the past 12 months. Studies indicate that despite the high prevalence of migraine, more than half of the participants may not seek treatment and majority of them self-medicate [40]. The low consultation rates may indicate that many affected people are unaware of the existence of effective treatments [3].

Our study results indicate a significant association of migraine with socio-demographic variables. Similar findings have been reported in various studies, where individuals with migraine headache were more likely to be female $[17,20,41]$. A possible explanation could be the effects of female sex hormones [3, 42]; hormonal changes in women occur throughout the menstrual cycle and during menopause which may cause migraine. Research has also shown that prevalence of migraine in women increases after the average age of menarche, and peaks before the average age of menopause, affecting most women during their childbearing years [43]

Ethnicity also appears to play a role in migraine headache; while individuals of Malay ethnicity were more likely than those of Chinese ethnicity to experience migraine in the current study, these findings are consistent with a previous study conducted in 2010 among Singapore's general population [20] as well as in the clinical population by Tai et al. [44]. Possible explanations could include the influence of culture, lifestyle, and dietary habits. Tai et al. suggest that diet may be a trigger (e.g., coffee, chocolate, sweet drinks, etc.) for migraine [44]. A study conducted in Malaysia by Abu-Salameh et al. among Malays reported that fasting may act as a trigger for migraine, and fasting is also associated with dehydration and caffeine withdrawal which may further aggravate migraine headache [31]. However, more research is needed to improve our understanding of the nutritional habits of the Malays to prevent or reduce migraine headache. Another local study conducted by Ho and Ong showed that those of Chinese ethnicity were significantly less likely to seek medical attention for migraine headache. Furthermore, it has been proposed that headache is considered an emotional problem or weakness in Chinese culture, which could lead to under-reporting of symptoms [45]. Thus, it is also possible that those of Malay ethnicity were more likely to seek medical attention for migraine resulting in an increased prevalence of clinician diagnosed migraine [46]. Chong et al. reported that cultural beliefs and practices including attitudes to pain as spiritual virtue among those of Malay ethnicity, and use of acupuncture and traditional Chinese medicine (TCM) among Chinese ethnic groups for pain conditions rather than Western medicine may affect health-seeking behaviours among the multi-ethnic local population [47].

Our study results are consistent with multiple epidemiological studies that have demonstrated that the prevalence of migraine headache is lower in elderly populations [7, 48]. One possible explanation could be that migraine decreases with advancing age; on the other hand, the incidence of migraine and its accompanying symptoms of photo sensitivity, nausea, and vomiting tend to be moderate in older adults compared with younger adults [49-51]. Another possible explanation could be migraine symptoms in the elderly population may be atypical due to their other comorbid medical conditions [52], medication overuse [53], and polypharmacy [54]. Our findings are in agreement with the previous population-based studies conducted in China [51], Italy [55], United States [30], and Japan [56] that have found migraine headache prevalence to decrease significantly with increasing age.

Interestingly, individuals who were economically inactive were less likely to have migraine headache compared to those who were employed. The possible reason could be economically inactive individuals included homemakers, student, retirees, or pensioners in our study, who may have less work-related stressors and fewer responsibilities. A research study by Corrêa et al. similarly found that active employees showed a greater tendency to have migraine than pensioners and retirees. A possible suggestion could be that employed individuals are more heavily exposed to triggering and aggravating factors including emotional stress in the work place [57]. A longitudinal study revealed that retirement is associated with a decrease in migraine prevalence, particularly among persons with a high amount of work stress or proneness to overreact to stress $[58,59]$. Other studies have found that those employed were significantly and positively associated with migraine headache which results in a reduction in work productivity and work absenteeism $[60,61]$.

Consistent with various research findings, our study also found an association of migraine headache with psychiatric disorders, including MDD, GAD, BD and OCD [10, $11,16,17,20,62]$. After adjusting for socio-demographic variables, migraine headache remained significantly associated with the above-mentioned psychiatric disorders as well as AUD. Few epidemiological studies have investigated whether individuals with migraine are significantly more likely to suffer from a psychiatric disorder than those without migraine headache, even after controlling for sociodemographic factors. Jette et al. and Hamelskv and Lipton reported that individuals with migraine were $2-5$ times more likely to be diagnosed with a depressive or anxiety disorder $[16,63]$. When we further adjusted for the presence of the other chronic conditions, migraine remained significantly 
associated with all psychiatric disorders compared to those without migraine, which is consistent with a previous local study [20] and other studies [12,32]. Studies on the association of migraine and bipolar disorder are fewer as compared to those with anxiety and depression. Few population-based studies have reported that migraine and bipolar disorder have a strong and positive association $[64,65]$.

Various mechanisms have been proposed to explain the association between migraine headache and psychiatric disorders. These include bidirectional association [10, 66], sharing of common genetic factors, and pathophysiological abnormalities such as serotonergic processing and oestrogen response [12]. A recent study by Anttila et al. using data from genome-wide association studies (GWAS) quantified the degree of overlap for genetic risk factors of 25 common brain disorders. While neurological disorders were distinct from one another and from the psychiatric disorders, migraine was significantly correlated with psychiatric disorders including attention deficit hyperactivity disorder and MDD [67]. Other GWAS and twin studies have similarly determined that shared underlying genetically determined disease mechanisms result in significant comorbidity between migraine and MDD [68]. Epidemiological surveys have revealed that most related symptoms of anxiety (such as worry, fear, muscle tension, irritability) and depression (such as fatigue, poor sleep, and appetite) are also part of the migraine clinical spectrum [69-71].

Individuals with migraine headache were significantly associated with reduced role functioning and disability compared to those without migraine in our sample. The current study results are consistent with the results of other population-based studies [72] as well as clinical trials [73]. Lipton et al. reported that migraine is associated with marked disability, with more than half of those with migraine reporting severe impairment in activity with reduced work or school productivity [72]. Another study similarly reported that $91 \%$ of participants reported limitations in everyday functioning while experiencing a migraine headache [60]. Saunders et al. found that individuals with migraine experienced role disability on $25.2 \%$ of the last 30 days compared with $9.7 \%$ days for an individual without migraine [74]. The substantial impact is because of its high prevalence, the burden on social relationships $[75,76]$, and its association with other comorbid conditions [77].

Our findings should be considered in light of the study's limitations. First, the prevalence of migraine was assessed through a single question and using self-report. While this provides an overview of the prevalence of migraine among the general population in Singapore, a more comprehensive tool may be required to develop a better understanding of migraine in the local population as a single-item selfreport measure is not as precise and reliable as a structured interview. Information regarding duration and frequency of migraine, diet patterns, and lifestyle is also needed to gain further insight into migraine headache in this population [44]. Second, about $30 \%$ of the randomly selected sample was not interviewed due to non-response which could have lead to an underestimation of the prevalence as individuals who refused to participate may have a higher prevalence of mental and physical illnesses. Third, participants may also have under-reported or been reluctant to report experiencing symptoms of migraine headache. Finally, the cross-sectional design of this study limited any causal inferences from being made. Self-reported data are subjected to recall bias which limited our ability to determine whether migraine headache and psychiatric conditions occurred at the same or different points of time in the participant's life. A bidirectional relationship between migraine headache and psychiatric conditions has been suggested in longitudinal studies, wherein it has been proposed that the burden and distress associated with migraines can cause or contribute to psychiatric disorders. In a longitudinal general population study of young adults, Breslau and Davis found that a history of migraine significantly increased the rate of first-time panic disorder, while a longitudinal study by Rist et al. found that middle-aged women with migraine were at increased risk of incident depression [78, 79]. On the other hand, a study by Mercante et al. reported that anxiety disorders preceded migraine headache in terms of age of onset. The onset of migraine tended to occur late in the anxiety group compared to controls, suggesting that migraines are a long-term consequence of untreated anxiety disorder [80]. A study by Merikangas et al. reported that anxiety was shown to precede migraine in most patients, which in turn preceded depression, and that the ages of onset of each disorder were significantly correlated [81]. Pine et al. found that major depression in adolescents predicted the new onset of headaches in young adulthood [82]. Thus, future studies with a longitudinal design are necessary to explore possible causal relationships.

These limitations notwithstanding, this is a single-phase assessment, using a well-established instrument with faceto-face interviews, which ensured accurate and detailed collection of information from all individuals. The study has a large sample size, with a high response rate that provides confidence in the results and improves generalizability.

\section{Conclusions}

The present study established that migraine headache is prevalent in Singapore with 1 in 12 people in the population having lifetime migraine headache. The study found a significant association between migraine headache and psychiatric disorders and established its negative impact on functioning and disability. These findings can help 
to create awareness and encourage holistic coordinated approaches to the management of migraine in health care settings.

Funding The study was funded by the Ministry of Health Singapore and Temasek Foundation Innovates.

\section{Compliance with ethical standards}

Conflict of interest The authors have no conflict of interest to declare.

Ethical approval The study was approved by the National Healthcare Groups' Domain Specific Review Board.

Informed consent Written informed consent was obtained from all participants and parents or legally acceptable representatives of those aged below 21 years.

Open Access This article is distributed under the terms of the Creative Commons Attribution 4.0 International License (http://creativeco mmons.org/licenses/by/4.0/), which permits unrestricted use, distribution, and reproduction in any medium, provided you give appropriate credit to the original author(s) and the source, provide a link to the Creative Commons license, and indicate if changes were made.

\section{References}

1. Charles A (2017) The pathophysiology of migraine: implications for clinical management. Lancet Neurol 17:174-182

2. Woldeamanuel YW (2017) Headache in resource-limited settings. Curr Pain Headache 21(12):51

3. World Health Organization (2011) Atlas of headache disorders and resources in the world 2011. World Health Organization, Geneva, $\mathrm{p} 72$

4. Jensen R, Stovner LJ (2008) Epidemiology and comorbidity of headache. Lancet Neurol 7(4):354-361

5. IHS HCSotIHS (2004) The international classification of headache disorders: 2nd edition. Cephalalgia 24(1):9-160

6. Streel S, Donneau A-F, Hoge A, Albert A, Schoenen J, Guillaume M (2015) One-year prevalence of migraine using a validated extended French version of the ID migraine ${ }^{\mathrm{TM}}$ : a Belgian population-based study. Rev Neurol 171(10):707-714

7. Stovner LJ, Zwart JA, Hagen K, Terwindt G, Pascual J (2006) Epidemiology of headache in Europe. Eur J Neurol 13(4):333-345

8. Wang S-J (2003) Epidemiology of migraine and other types of headache in Asia. Curr Neurol Neurosci 3(2):104-108

9. Minen MT, De Dhaem OB, Van Diest AK, Powers S, Schwedt TJ, Lipton R et al (2016) Migraine and its psychiatric comorbidities. J Neurol Neurosurg Psychiatry 87(7):741-749

10. Bruti G, Magnotti M, Iannetti G (2012) Migraine and depression: bidirectional co-morbidities? Neurol Sci 33(1):107-109

11. Sivaji M, Manickavasagam J, Sundaramurthi I, Gopinathan S (2017) A study on prevalence and co-morbidity of bipolar and anxiety disorders in chronic headache patients. Int J Res Med Sci 5(7):3038-3043

12. Peterlin BL, Katsnelson MJ, Calhoun AH (2009) The associations between migraine, unipolar psychiatric comorbidities, and stressrelated disorders and the role of estrogen. Curr Pain Headache 13(5):404-412
13. Soares CN, Poitras JR, Prouty J (2003) Effect of reproductive hormones and selective estrogen receptor modulators on mood during menopause. Drugs Aging 20(2):85-100

14. Scher AI, Rizzoli PB, Loder EW (2017) Medication overuse headache: an entrenched idea in need of scrutiny. Neurology 89(12):1296-1304

15. Rains JC (2008) Chronic headache and potentially modifiable risk factors: screening and behavioral management of sleep disorders. Headache 48(1):32-39

16. Jette N, Patten S, Williams J, Becker W, Wiebe S (2008) Comorbidity of migraine and psychiatric disorders-a national population-based study. Headache 48(4):501-516

17. Risal A, Manandhar K, Holen A, Steiner TJ, Linde M (2016) Comorbidities of psychiatric and headache disorders in Nepal: implications from a nationwide population-based study. J Headache Pain 17(1):45

18. Mannix S, Skalicky A, Buse DC, Desai P, Sapra S, Ortmeier B et al (2016) Measuring the impact of migraine for evaluating outcomes of preventive treatments for migraine headaches. Health Qual Life Outcomes 14(1):143

19. Teixeira AL, Costa EAC, da Silva AA, dos Santos IAM, Gómez RS, Kummer A et al (2012) Psychiatric comorbidities of chronic migraine in community and tertiary care clinic samples. J Headache Pain 13(7):551

20. Subramaniam M, Vaingankar JA, Abdin E, Chong SA (2013) Psychiatric morbidity in pain conditions: results from the Singapore Mental Health Study. Pain Res Manag 18(4):185-190

21. Lee S, Tsang A, Von Korff M, De Graaf R, Benjet C, Haro JM et al (2009) Association of headache with childhood adversity and mental disorder: cross-national study. Br J Psychiatry 194(2):111-116

22. Ertas M, Baykan B, Orhan EK, Zarifoglu M, Karli N, Saip S et al (2012) One-year prevalence and the impact of migraine and tension-type headache in Turkey: a nationwide home-based study in adults. J Headache Pain 13(2):147-157

23. Stewart WF, Roy J, Lipton RB (2013) Migraine prevalence, socioeconomic status, and social causation. Neurology. https://doi. org/10.1212/wnl.0b013e3182a43b32

24. Khu J, Siow H, Ho K (2008) Headache diagnosis, management and morbidity in the Singapore primary care setting: findings from a general practice survey. Singap Med J 49(10):774

25. Subramaniam M, Abdin E, Vaingankar JA, Shafie S, Chua BY, Sambasivam R et al (2019) Tracking the mental health of a nation: prevalence and correlates of mental disorders in the second Singapore Mental Health Study. Epidemiol Psychiatr Sci. https://doi. org/10.1017/S2045796019000179

26. Singapore Department of Statistics (2014) Population trends 2014. Retrieved from https://www.singstat.gov.sg/modules/infographics/ population

27. Kessler RC, Üstün TB (2004) The World Mental Health (WMH) survey initiative version of the World Health Organization (WHO) composite international diagnostic interview (CIDI). Int J Methods Psychiatr Res 13(2):93-121

28. SAS Institute Inc (2011) SAS/STAT® 9.3 User' guide. SAS Institute, Cary, NC

29. Zou G (2004) A modified poisson regression approach to prospective studies with binary data. Am J Epidemiol 159(7):702-706

30. Victor T, Hu X, Campbell J, Buse D, Lipton R (2010) Migraine prevalence by age and sex in the United States: a life-span study. Cephalalgia 30(9): 1065-1072

31. Abu-Salameh I, Plakht Y, Ifergane G (2010) Migraine exacerbation during Ramadan fasting. J Headache Pain 11(6):513-517

32. McWilliams LA, Goodwin RD, Cox BJ (2004) Depression and anxiety associated with three pain conditions: results from a nationally representative sample. Pain 111(1-2):77-83 
33. Sauro KM, Becker WJ (2009) The stress and migraine interaction. Headache 49(9):1378-1386

34. Robberstad L, Dyb G, Hagen K, Stovner L, Holmen T, Zwart J-A (2010) An unfavorable lifestyle and recurrent headaches among adolescents: the HUNT study. Neurology 75(8):712-717

35. National Population Health Survey (2016) National Population Health Survey 2016/17-Ministry of Health. https://www.moh.gov. $\mathrm{sg} /$ resources-statistics/reports/national-population-health-surve y-2016-17. Accessed 4 Jun 2019

36. Huang Q, Liang X, Wang S, Mu X (2018) Association between body mass index and migraine: a survey of adult population in China. Behav Neurol. https://doi.org/10.1155/2018/6585734

37. Egli M, Koob GF, Edwards S (2012) Alcohol dependence as a chronic pain disorder. Neurosci Biobehav Rev 36(10):2179-2192

38. Burch R, Rizzoli P, Loder E (2018) The prevalence and impact of migraine and severe headache in the United States: figures and trends from government health studies. Headache 58(4):496-505

39. Yeh WZ, Blizzard L, Taylor BV (2018) What is the actual prevalence of migraine? Brain Behav 8(6):e00950

40. Ghumman SS, Nadeem M, Nawaz AJ, Azeem MU, Khan ZH, Mazhar SM (2013) Self-management of headache: a cross-sectional survey in the general public of Islamabad. J Pak Med Assoc 63(9):1210-1214

41. Buse DC, Loder EW, Gorman JA, Stewart WF, Reed ML, Fanning $\mathrm{KM}$ et al (2013) Sex differences in the prevalence, symptoms, and associated features of migraine, probable migraine and other severe headache: results of the American Migraine Prevalence and Prevention (AMPP) study. Headache 53(8):1278-1299

42. Kachouei H, Ameli J, Sharifi BM, Tavalaei SA, Keshavarzi N, Karami GR (2006) Evaluation of provocating factors of migraine attacks. Kowsar Med J 11:279-284

43. Karlı N, Baykan B, Ertaş M, Zarifoğlu M, Siva A, Saip S et al (2012) Impact of sex hormonal changes on tension-type headache and migraine: a cross-sectional population-based survey in 2600 women. J Headache Pain 13(7):557-565

44. Tai M-LS, Yap JF, Goh CB (2018) Dietary trigger factors of migraine and tension-type headache in a south east Asian country. J Pain Res 11:1255

45. Ho K, Ong B-C (2003) A community-based study of headache diagnosis and prevalence in Singapore. Cephalalgia 23(1):6-13

46. Ho KH, Ong BK (2001) Headache characteristics and race in Singapore: results of a randomized national survey. J Head Face Pain 41(3):279-284

47. Chong SC, Chan YH, Ong HT, Low PS, Tay SK (2010) Headache diagnosis, disability and co-morbidities in a multi-ethnic, heterogeneous paediatric Asian population. Cephalalgia 30(8):953-961

48. Miranda H, Ortiz G, Figueroa S, Peña D, Guzmán J (2003) Prevalence of headache in Puerto Rico. Headache 43(7):774-778

49. Tai M-LS, Jivanadham JS, Tan CT, Sharma VK (2012) Primary headache in the elderly in south-east Asia. J Headache Pain 13(4):291-297

50. Ruiz M, Pedraza M, de La Cruz C, Barón J, Muñoz I, Rodríguez $\mathrm{C}$ et al (2014) Headache in the elderly: a series of 262 patients. Neurología 29(6):321-326

51. Zhang Y, Shi Z, Hock D, Yue W, Liu S, Zhang Y et al (2016) Prevalence of primary headache disorders in a population aged 60 years and older in a rural area of Northern China. J Headache Pain 17(1):83

52. Starling AJ (2018) Diagnosis and management of headache in older adults. Mayo Clin Proc 93:252-262

53. Song T-J, Kim Y-J, Kim B-K, Kim B-S, Kim J-M, Kim S-K et al (2016) Characteristics of elderly-onset ( $\geq 65$ years) headache diagnosed using the international classification of headache disorders, beta version. J Clin Neurol 12(4):419-425
54. de Rijk P, Resseguier N, Donnet A (2018) Headache characteristics and clinical features of elderly migraine patients. Headache 58(4):525-533

55. Camarda R, Monastero R (2003) Prevalence of primary headaches in Italian elderly: preliminary data from the Zabut Aging Project. Neurol Sci 24(2):s122-s124

56. Takeshima T, Ishizaki K, Fukuhara Y, Ijiri T, Kusumi M, Wakutani Y et al (2004) Population-based door-to-door survey of migraine in Japan: the Daisen study. Headache 44(1):8-19

57. Corrêa TS, Santos KM, Galato D (2010) Prevalence and management of headache in a selected area of Southern Santa Catarina. Arq Neuro-Psiquiatr 68(2):216-223

58. Westerlund H, Kivimäki M, Singh-Manoux A, Melchior M, Ferrie JE, Pentti J, Jokela M, Leineweber C, Goldberg M, Zins M, Vahtera J (2009) Self-rated health before and after retirement in France (GAZEL): a cohort study. Lancet 374(9705):1889-1896

59. Sjösten N, Nabi H, Westerlund H, Singh-Manoux A, Dartigues JF, Goldberg M, Zins M, Oksanen T, Salo P, Pentti J, Kivimäki M, Vahtera J (2012) Influence of retirement and work stress on headache prevalence: a longitudinal modelling study from the GAZEL Cohort. Cephalalgia 31(6):696-705

60. Lipton RB, Stewart WF, Diamond S, Diamond ML, Reed M (2001) Prevalence and burden of migraine in the United States: data from the American Migraine Study II. Headache 41(7):646-657

61. Kessler RC, Shahly V, Stang PE, Lane MC (2010) The associations of migraines and other headaches with work performance: results from the National Comorbidity Survey Replication (NCS-R). Cephalalgia 30(6):722-734

62. Harnod T, Lin C-L, Kao C-H (2018) Survival outcome and mortality rate in patients with migraine: a population-based cohort study. J Headache 19(1):57

63. Hamelsky SW, Lipton RB (2006) Psychiatric comorbidity of migraine. Headache 46(9):1327-1333

64. Antonaci F, Nappi G, Galli F, Manzoni GC, Calabresi P, Costa A (2011) Migraine and psychiatric comorbidity: a review of clinical findings. J Headache Pain 12(2):115

65. Ortiz A, Cervantes P, Zlotnik G, Van De Velde C, Slaney C, Garnham J et al (2010) Cross-prevalence of migraine and bipolar disorder. Bipolar Disord 12(4):397-403

66. Goulart AC, Santos IS, Brunoni AR, Nunes MA, Passos VM, Griep RH et al (2014) Migraine headaches and mood/anxiety disorders in the ELSA Brazil. Headache 54(8):1310-1319

67. Anttila V, Bulik-Sullivan B, Finucane HK et al (2018) Analysis of shared heritability in common disorders of the brain. Science 360(6395): eaap8757

68. Yang Y, Zhao H, Heath AC, Madden PA, Martin NG, Nyholt DR (2016) Shared genetic factors underlie migraine and depression. Twin Res Hum Genet 19(4):341-350

69. Peres MFP, Mercante JP, Tobo PR, Kamei H, Bigal ME (2017) Anxiety and depression symptoms and migraine: a symptombased approach research. J Headache Pain 18(1):37

70. Arendt-Nielsen L (2015) Headache: muscle tension, trigger points and referred pain. Int J Clin Pract Suppl 182:8-12

71. Bigal ME (2012) The association between migraine and obesity: empty calories? Cephalalgia 13(32):950-952

72. Lipton RB, Bigal ME, Scher AI, Stewart WF (2003) The global burden of migraine. J Headache Pain 4(1):s3-s11

73. Shin HE, Park JW, Kim YI, Lee KS (2008) Headache Impact Test-6 (HIT-6) scores for migraine patients: their relation to disability as measured from a headache diary. J Clin Neurol 4(4): $158-163$

74. Saunders K, Merikangas K, Low N, Von Korff M, Kessler R (2008) Impact of comorbidity on headache-related disability. Neurology 70(7):538-547 
75. Stovner LJ, Andree C (2010) Prevalence of headache in Europe: a review for the Eurolight project. J Headache Pain 11(4):289

76. Kandil MR, Hamed SA, Fadel KA-M, Khalifa HE, Ghanem MK, Mohamed KO (2016) Migraine in Assiut governorate, Egypt: epidemiology, risk factors, comorbid conditions and predictors of change from episodic to chronic migraine. J Neurol Res 38(3):232-241

77. Smitherman TA, Burch R, Sheikh H, Loder E (2013) The prevalence, impact, and treatment of migraine and severe headaches in the United States: a review of statistics from national surveillance studies. Headache 53(3):427-436

78. Breslau N, Davis G (1993) Migraine, physical health and psychiatric disorder: a prospective epidemiologic study in young adults. J Psychiatry Res 27(2):211-221
79. Rist PMSM, Buring JE, Kurth T (2013) Migraine, headache, and the risk of depression: prospective cohort study. Cephalalgia 33(12):1017-1025

80. Mercante J, Peres M, Bernik M (2011) Primary headaches in patients with generalized anxiety disorder. J Headache Pain 12(3):331-338

81. Merikangas K, Angst J, Isler H (1990) Migraine and psychopathology: results of the Zurich cohort study of young adults. Arch Gen Psychiatry 47(9):849-853

82. Pine D, Cohen P, Brook J (1996) The association between major depression and headache: results of a longitudinal epidemilogic study in youth. J Child Adolesc Psychopharmacol 6(3):153-164

\section{Affiliations}

\section{Anitha Jeyagurunathan ${ }^{1}$ (D) Edimansyah Abdin ${ }^{1}$. Janhavi Ajit Vaingankar ${ }^{1}$ - Boon Yiang Chua ${ }^{1}$. Saleha Shafie ${ }^{1}$. Shi Hui Sherilyn Chang ${ }^{1} \cdot$ Lyn James $^{2} \cdot{\text { Kelvin Bryan } \operatorname{Tan}^{2} \cdot \text { Sutapa Basu }}^{3} \cdot$ Siow Ann Chong ${ }^{1} \cdot$ Mythily Subramaniam $^{1}$}

\author{
Edimansyah Abdin \\ edimansyah_abdin@imh.com.sg \\ Janhavi Ajit Vaingankar \\ janhavi_vaingankar@imh.com.sg \\ Boon Yiang Chua \\ boon_yiang_chua@imh.com.sg \\ Saleha Shafie \\ saleha_shafie@imh.com.sg \\ Shi Hui Sherilyn Chang \\ Sherilyn_Sh_CHANG@imh.com.sg \\ Lyn James \\ Lyn_JAMES@moh.gov.sg \\ Kelvin Bryan Tan \\ Kelvin_Bryan_TAN@moh.gov.sg
}

Sutapa Basu

sutapa_basu@imh.com.sg

Siow Ann Chong

siow_ann_chong@imh.com.sg

Mythily Subramaniam

mythily@imh.com.sg

1 Research Division, Institute of Mental Health (IMH), Buangkok Green Medical Park, 10 Buangkok View, Singapore 539747, Singapore

2 Ministry of Health (MOH), Singapore, Singapore

3 Early Psychosis Intervention Programme (EPIP), Department of Psychosis, IMH, Singapore, Singapore 